\title{
1. Leading for creativity: Functions, models, and domains
}

\author{
Michael D. Mumford, Sven Hemlin, and Tyler J. Mulhearn
}

The rapid pace of technological change, the increased pressure of competitive intensity, and globalization of competition, products, and services have had a noteworthy impact on firms across the world. These forces have conspired to place a new premium on innovation (Dess \& Pickens, 2000; Mumford \& Hunter, 2005). Indeed, the success of firms such as Disney, General Electric, IBM, Apple, and Intel has long been linked to their ability to develop and field innovative new products and services. Today, however, even firms once considered not especially innovative have found their success and survival to depend on creativity and innovation - consider, for example, General Motors. Other firms working in fields never considered especially creative have become successful as a result of innovation - for example, Walmart in retail or Waste Management in disposal systems.

The ability of these firms to produce innovative new products and services, however, ultimately depends on the ability of the firm to manage and stimulate creative thinking on the part of its employees (Amabile, 1996; Denti \& Hemlin, 2012; Eisenbeiss, van Knippenberg, \& Boerner, 2008). Creative thinking at work, however, is influenced by many variables. For example, people's expertise is a crucial influence on their ability to do creative work (Weisberg \& Hass, 2007). The way people work with expertise to produce innovative problem-solutions, how they define problems, combine extant concepts, and generate ideas is also of real importance (Barrett, Vessey, Griffith, Mracek, \& Mumford, 2014; Hemlin \& Olsson, 2011; Mumford, Medeiros, \& Partlow, 2012). Creative people, moreover, must evidence an open, autonomous work style. And, given the risks of creative work, they must evidence a sense of self-efficacy - creative self-efficacy (Tierney, Farmer, \& Graen, 1999).

Creative work, however, is not simply a matter of people's capacity, style, and motivation. Creative work, like all other work, occurs in an organizational context - sometimes in a formal organizational context, in a firm, and at other times, in a less formal, professional context. What is of note here, however, is that the organizational context is a powerful force shaping the nature and success of creative efforts (Oldham \& Cummings, 1996). The success of creative efforts and people's willingness to make the substantial investments required in most creative efforts depends, in part, on their appraisal of available resources (Nohria \& Gulati, 1996). It depends on the processes by which work is accomplished in the firm (Hülsheger, Anderson, \& Salgado, 2009). It depends on how firms structure themselves (Damanpour \& Schneider, 2006). It depends on how firms structure communication and interpersonal exchange (Baer, 2012). And, it depends on people's perception of the support for creativity evident in their immediate work environment (Amabile, Conti, Coon, Lazenby, \& Herron, 1996).

We do not wish to dispute the importance of these, and a number of other variables that act to influence creativity in organizational settings. However, one variable has been 


\section{Handbook of research on leadership and creativity}

found to be of special significance - the behavior of those asked to lead creative efforts (Mumford, Scott, Gaddis, \& Strange, 2002). To many, the impact of leader behavior on employee creativity is something of a surprise. Traditionally, we have understood creativity in terms of the unique genius of creative people. In this view of creative work, the leader of a firm, or a team given a creative task, is little more than a supporting player (Agars, Kaufman, Deane, \& Smith, 2012), and, a supporting player is of not much interest in our attempts to understand creativity at work - creativity in organizations. However, the evidence accrued in many studies indicates that effective leadership is critical to both the success of creative efforts and people's willingness to invest in these creative efforts.

For example, Pelz and Andrews (1966) examined the productivity of research and development teams and found that supervisory behavior - leader behavior - was strongly related $(r \approx 0.30)$ to production of creative products such as publications. In another study, Andrews and Farris (1967) asked peers working in research laboratories to appraise the innovation, productivity, significance of contributions made, and the usefulness of the work of 94 research and development personnel working in 21 teams. Followers assessed leader technical competence, relations with subordinates, and leader administration of the team. It was found that leader technical, relational, and administrative skills were correlated - positively correlated - with ratings of innovation in the 0.30 to 0.50 range. In another study, Barnowe (1975) examined 963 research and development chemists working in 81 teams. Leader technical skill, support, structuring, participation, and closeness of supervision were assessed by reports from these chemists. It was found that leader technical skill, support, structuring, and encouragement of participation were correlated in the 0.40 s with measures of innovation.

More recent studies have served to confirm these early findings. For example, Kim, Min, and Cha (1999), in a study of 87 research and development teams, found that team performance was positively related to leader technical skill, team building, gate keeping, and strategic planning. Tierney et al. (1999), in a study of 191 research managers, found that leader behavior was positively related not only to team member publications but, more notably, to invention disclosures. Scott and Bruce (1998) found that positive leader-member exchange was strongly, positively related to senior managers' appraisal of innovation. Keller (2006) examined the impact of transformational leadership and leader structuring behavior on the technical quality, schedule performance, cost performance, and speed to market of the products being developed by 118 research and development teams. It was found that both transformational leadership and leader-initiating structure were positively - strongly positively - related to these indices of the success of teams' creative efforts - producing relationships in the 0.30 to 0.40 range. Still other work by Carmeli, Reiter-Palmon, and Ziv (2010) has provided evidence indicating leader behavior influences the engagement of followers in creative tasks - in part, as a result of feelings of psychological safety.

Although other studies might be cited, the studies cited above lead to three key conclusions. First, leaders are not just supporters of others' creative work. They have an impact, a big impact - an impact in the 0.40 range -with various indices of success of creative efforts (e.g., Barnowe, 1975). Effects of this size indicate that leaders, and leader behavior, may be the most powerful influences on the success of creative efforts.

Second, these effects do not appear to be level bound. Thus, some studies have shown that leaders influence the performance of research and development teams (e.g., Keller, 
2006). Other studies have shown that dyadic relationships between leaders and followers influence follower creativity (e.g., Tierney et al., 1999). Still other studies have shown that leadership behavior influences the performance of individuals asked to do creative work (e.g., Barnowe, 1975). Thus, leaders exert influence on the creativity of teams, dyads, and individuals. This broad impact indicates that leaders are not only a powerful force on follower creativity, they are also a powerful force operating at multiple levels of analysis.

Third, these effects are not limited to simply "academic" outcomes such as papers published. Effective leadership is positively related - strongly positively related - to hard, tangible outcomes sought by firms. Thus, effective leadership is positively related to invention disclosures - the basis for innovative new products produced by many firms (e.g., Tierney et al., 1999). Not only is effective leadership positively related to fielding viable new products, it is also positively related to cost and schedule performance in the development and fielding of new products.

The strong, positive effects, effects exerted across levels of analysis, on multiple, concrete outcomes, indicate that leadership is a critical force shaping creativity and innovation in firms. Recognition of the strong, positive impact of leaders on firm innovation and worker creativity has resulted in a new interest in the impact of leaders and leaders' behavior on creativity and innovation (Mainemelis, Kark, \& Epitropaki, 2015; Mumford, Gibson, Giorgini, \& Mecca, 2014). Our intention in this chapter is to summarize the main themes of research on leader behavior and capacities contributing to follower creativity. Moreover, in the course of this, we hope to identify some critical new directions for future research into leader impacts on follower creativity.

The handbook is divided into three major parts: (I) leadership functions, (II) leadership models, and (III) leadership in different domains of creative activity. Work in each of these areas is critical to understanding the nature and significance of leadership in the creative enterprise. And, the work evident in each of these three key areas - functions, models, domains - is of great significance in understanding how leaders act to shape the nature and success of creative efforts.

The term "functions" refers to those key activities that must be executed by leaders if creative efforts are to prove successful (Fleishman et al., 1992). For example, leaders must sell creative efforts to others in the firm - a function referred to as championing (Howell \& Boies, 2004). Leaders must also plan the work of project teams and evaluate the work produced by these teams (Andrews \& Farris, 1967). Leaders, moreover, must motivate creative efforts and establish a climate that will support creativity (West \& Sacramento, 2012). The eight chapters included in this part will examine (1) leader planning, (2) learning, (3) championing, (4) evaluating creative work, (5) motivating creative people, (6) establishing a creative climate, (7) managing creative teams, and (8) innovating/ executing.

The next part, leadership models, attempts to explain creative leadership using available theoretical models intended to account for leadership behavior in general, looking at the effects of these leader behaviors on follower creativity. The seven chapters included in this part examine (1) leader consideration and initiating structure, (2) leader-member exchange, (3) transformational leadership, (4) participative/shared leadership, (5) collective leadership, (6) charismatic, ideological, and pragmatic leadership, and (7) leader roles. Each of these models, some old (e.g., consideration and initiating structure) and some new (e.g., charismatic, ideological, and pragmatic leadership) have been used to account for 
the key behaviors, behaviors applying across domains, that might account for the performance of those asked to lead creative efforts.

The final part examines leadership in some, although certainly not all domains, where organizations seek creativity. Some of the domains examined, for example, leadership of research and development teams or leadership in business settings, represent areas that have traditionally been held to call for creativity. Other domains, for example, leadership in the military and academic leadership, have not, at least traditionally, been viewed as domains where creative leadership is critical - although the authors argue it may, in fact, prove critical. The seven domains examined include (1) executive leadership, (2) business leadership, (3) military leadership, (4) leadership in academic settings, (5) leadership in marketing, (6) leadership in the arts, and (7) leadership in research and development.

\section{PART I: FUNCTIONS}

One critical function that must be performed by those asked to lead creative efforts is planning. Although many scholars look askance at planning (Mintzberg, 1991), creative efforts in real-world settings are capital short, and often capital intensive, where the outcomes of actions are inherently uncertain in a dynamic, competitive environment. As Dean and Sharfman (1996) note, it is exactly under these conditions where planning planning by leaders - is critical to performance. Indeed, those asked to lead creative efforts may delegate much but they do not delegate planning (Hemlin, 2009).

Mumford, Steele, Mulhearn, McIntosh, and Watts, in Chapter 2 of this handbook, argue that leaders' plans are constructed using experiential, case-based, knowledge and mental models. Thus, to lead creative efforts, leaders must have technical expertise. This knowledge, however, is not sufficient to ensure viable plans. Leaders must actively work with this knowledge, knowledge of the past, to plan for the future. In the view of Mumford et al., leader planning for creative efforts is both adaptive and opportunistic - allowing leaders to spot, and exploit, emergent opportunities. Thus, they stress the need for leaders to monitor the technical environment, analyze key causes, and forecast the downstream implications of new technologies and new needs. Indeed, O'Connor (1998) has found that such forecasting skills characterize those who have led the development of radical new innovations. What we now need is research on how leaders should go about appraising the impact of key causes and forecasting the effects of their actions on both followers and followers' actual work.

Plans for creative efforts, of course, do not always work out with respect to fielding new products and services. Thus, leaders must learn both from experience and their forecasts. In fact, Cohen and Levinthal (1990) have argued that leader learning is a key function that serves to provide firms with absorptive capacity - an understanding of the implications of new technologies or new processes. Kazanjian, in Chapter 3, examines how learning influences the performance of those asked to lead creative efforts. He argues that learning in firms is inherently a multi-level phenomenon occurring at the individual, team, and firm levels. More centrally, he argues that it is learning about interdependencies that is critical to the leadership of creative efforts. For example, how might a project on spatial imaging contribute to crop rotation? Indeed, we need work on how leaders seek out, appraise, and act on these interdependencies as they plan creative efforts in organizations. 
Leaders of creative efforts must plan, and they must learn both for themselves and the firm as a whole. However, planning and learning provide leaders with a basis for selling their projects to the firm (Howell \& Boies, 2004). In the field of creativity, sales is subsumed under the rubric of championing. Markham and Smith, in Chapter 4, argue that the leaders of creative efforts may take on a number of different championing roles - roles that are critical to the success of creative efforts. This observation is noteworthy because it implies that the leadership of creative efforts is not a "dry, dusty" activity. It requires constant social interaction with the firm and key constituencies within the firm. It also implies that sales skills and championing warrant far more attention in the study of creative leadership than they have to date received.

Leaders, however, must not only sell projects to the firm, they must also sell projects to those who will be doing the creative work - sales that must be made on a rather different basis due to the autonomy and professionalism that characterizes creative people (Feist, 1998). Not only must leaders sell their plans to followers, they must also evaluate the value of followers' work. In Chapter 5, Watts, Mulhearn, Todd, and Mumford examine the impact of leader idea evaluation on creative efforts. They argue that leaders' evaluation of creative work, or creative ideas, is crucial to the success of creative efforts, with leaders acting as a sounding board for the progressive improvement of ideas. They note, however, that such idea evaluation will depend on domain expertise, idea evaluation skills, feedback delivery skills, and constraint management skills. Of these capacities, perhaps constraint management skills are the most unique. However, all firms, and any creative effort, are subject to many constraints and leaders must help the firm and followers adapt to, work within, and work on changing these constraints if they are to provide effective, viable feedback. Unfortunately, empirical research on leaders' management of constraints has been lacking (Medeiros, Partlow, \& Mumford, 2014; Medeiros, Watts, \& Mumford, 2016) - pointing to a noteworthy direction for future research.

Leaders' ability to help followers manage constraints, professional, technical, organizational, or social, in their work is one way that leaders might motivate creative people. Motivation, however, has long been a concern in studies of creative leadership, with work examining how leaders might build motivation through participation (Zhang \& Bartol, 2010), feelings of creative self-efficacy (Tierney \& Farmer, 2002), and establishing learning goals (Hirst, van Knippenberg, \& Zhou, 2009). Steele, McIntosh, and Higgs, in Chapter 6, integrate these, and other models of motivation in a self-regulatory framework that holds that leaders must help followers channel motivation. Notably, they argue that leaders often encourage motivational self-regulation through actions taken on both extrinsic (e.g., pay) and intrinsic (e.g., interests) outcomes, arguing that leaders' actions to motivate followers through extrinsic and intrinsic outcomes must occur in a synergistic fashion that takes into account the specific nature of the task at hand. Unfortunately, too many studies of motivation for creative work have sought global conclusions. More work is needed to examine what conditions call for what motivating actions on the part of those asked to lead creative efforts.

Motivation for creative work is important because creativity is discretionary - people decide when, where, and how to be creative (Mumford et al., 2014). The impact of environmental appraisal on people's willingness to engage in creative work has led to a focus on how climate perceptions contribute to creativity - and, in fact, climate perceptions such as mission significance, peer support, and intellectual stimulation all contribute to 
creativity (Hunter, Bedell, \& Mumford, 2007). In Chapter 7, Isaksen takes these findings a step forward. He examines how the actions taken by leaders - specific actions - can result in the creation of a climate likely to encourage creativity. These observations are pragmatically important. However, given the complexity of climate and the many actions that Isaksen argues might contribute to a climate for creativity, a new question comes to the fore. What actions for what groups working on what products are most likely to have the strongest effects in establishing a climate for creativity?

Climate, and the actions taken by leaders to establish a climate for creativity, are also of note because climate influences the actions and interactions of teams asked to work on creative projects. In Chapter 8, Reiter-Palmon and Royster in fact argue that leaders in managing teams establish a climate that may, or may not, support creative work. They note, however, that leaders' management of creative teams is far more complex than simply establishing climate. In their view, leaders must also establish effective team processes, manage team interactions, manage conflict among team members to ensure it is professional, not personal, and encourage information sharing. Notably, however, ReiterPalmon and Royster argue that leaders must also manage cross-team interactions - a requirement that has taken on greater significance as team structures have become more complex and more transitory. In fact, more research is needed on how leaders manage transitory functional diversity than is available at this juncture. Such research may prove especially valuable given the role of cross-functional teams in firm innovation.

Kratzer and Michelfelder, in Chapter 9, examine how leaders bring creative ideas to fruition - deployment of innovative new products and services. They argue that innovation - new products or processes - is a complex activity in organizational settings. Moreover, the networks operating in an organization - informal, work flow, and external - are key vectors on which leaders must act when championing new products or new processes. They argue, moreover, that leaders, in acting on these networks, need both strong and weak ties to the network adapting to local demands made by these networks through ambidexterity. These observations are noteworthy not only because they point to the possibility that leaders of creative efforts need skills in establishing network relationships, they also suggest that leaders must interact with these relational networks in a flexible fashion as indicated by current project needs. What is less clear, however, is how those interaction patterns will change as projects move from initial inception to final deployment (Mumford, Bedell-Avers, \& Hunter, 2008).

\section{PART II: MODELS}

Although leaders must execute these functions - planning, evaluating, championing leaders' execution of many of these functions, for example, planning (Marta, Leritz, \& Mumford, 2005) may not be observable to followers. Followers do, however, appraise and respond to the behaviors of leaders they can see. In fact, much research on the leadership of creative efforts has focused on those leader behaviors that followers can observe. And, typically, these studies are embedded in broader models of leadership behavior.

The earliest behavioral model of leadership was Fleishman's (1953) distinction between leader structuring behavior and leader consideration. And, over the years, a number of studies have examined how follower appraisals of leader structuring and consideration 
are related to creativity and innovation. In Chapter 10, Ligon and Derrick review the available studies of initiating structure and consideration on creativity and innovation. They remind us of one important finding: leader structuring may be as important as leader consideration in creative work. Ligon and Derrick, however, argue that merits of structuring and consideration will vary as a function of the stage, early versus late, of idea development and that different patterns of structuring and considerate behaviors may be required as leaders seek to influence individuals, teams, and the organization as a whole. This observation, however, brings to fore a new question - how do leaders balance, and integrate, structuring and consideration behaviors across multiple different targets operating at different, and interactive, levels of analysis?

Another key behavioral model of leadership is leader-member exchange (Graen \& UhlBien, 1995). Leader-member exchange (LMX) theory holds that perceptions of positive relationships with the leader, positive relationships arising from followers' competence, integrity, and commitment, as perceived by the leader, give rise to perceptions of leader support, greater follower self-efficacy, and more rapid growth of requisite skills - all variables contributing to subsequent creativity (Tierney et al., 1999). Olsson, in Chapter 11, provides evidence from 92 research teams for this anticipated relationship. However, her findings remind us that it is the leader's perception, not the follower's perception, of positive exchange relationships that predicts creative achievement. Thus, followers may hate their boss but if the boss likes the follower, all will turn out well. This finding is noteworthy because it suggests that creative performance, in contrast to other performances, may depend more on the leader than follower perceptions.

In keeping with this observation, other leadership models have focused more on the behavior of the leader than follower perceptions as the key influence on creative achievement. One widely applied model of effective leadership behavior is Bass's (1985) theory of transformational leadership. This theory holds that high-impact leaders evidence four types of behavior: (1) idealized influence (e.g., providing purpose), (2) inspirational motivation (e.g., engaging missions), (3) intellectual stimulation (e.g., challenging assumptions), and (4) individualized consideration (e.g., supporting followers as people). In Chapter 12, Rosing reviews the available literature on the impact of transformational leadership on follower and team creativity, arguing that only a weak positive relationship is observed, sometimes a negative relationship (Jaussi \& Dionne, 2003), with the effects of transformational leadership on follower creativity being moderated by level and function. Thus, individual-focused transformational behavior may reduce team knowledge - knowledge critical to creative efforts - while team-focused transformational leadership may increase the knowledge sharing needed for creative efforts. Thus, the value of any leader behavior may be contingent on key follower activities and the level at which these activities must occur. Although this proposition is plausible, research is needed to explicate the level at which leaders should try to act.

Theories of transformational leadership, however, assume the leader is the boss - the one calling the shots. Creative people, however, are autonomous and critical. As a result, many have argued that the most effective leadership of creative people is evident in leadership behavior that gives followers some control - shared leadership. Stephens and Carmeli, in Chapter 13, employ a positive theoretical framework to account for the value of shared leadership. They argue that respectful engagement of followers and follower caring evidenced by the leader enhances follower motivation, which, in turn, contributes 
to creativity. Thus, leaders should exhibit behaviors, for example, power sharing, that help followers thrive. Although some evidence supports this framework, in general, it is less clear when and how it works when followers are already motivated or motivated by different types of leader behavior such as the inspirational motivation of transformational leaders.

A related, albeit different, model of leader behavior holds that leadership is, ultimately, a collective activity where the role of the leader is to bring to bear relevant expertise to the particular problem currently confronting the team (Friedrich, Vessey, Schuelke, Ruark, \& Mumford, 2009; Friedrich et al., 2014). In Chapter 14, Friedrich and Zhong examine the impact of collective leadership on creative efforts. They argue that effective leaders must develop and exploit (communicate with) networks of expertise in leading creative projects. Put more directly, they must know who they are working with, their expertise, and how this expertise influences performance - empowering followers and delegating to them as dictated by current needs. They provide some support for this argument based on studies of consultation, communication, and feedback. However, these observations point to a broader concern: it may be more difficult for a leader to lead a collective than to lead through shared, transformational, or LMX behaviors.

One important implication of collective leadership is that different types of expertise may be needed in leading creative efforts or different styles of leadership. In fact, work by Koberg, Uhlenbruck, and Sarason (1996) indicates that creative projects are more likely to prove successful when multiple different types of leaders filling different roles are involved. Lovelace, Neely, Jayne, and Hunter, in Chapter 15, examine three distinct styles of vision-based leadership: (1) charismatic - a positive future vision, (2) ideological - a negative vision grounded in the past, and (3) pragmatic - a balanced adaptive vision focused on action in the present. Lovelace et al. argue that different leadership styles may prove particularly valuable at certain stages in creative projects. Thus, they argue that pragmatic leadership may prove especially valuable in early idea generation while charismatic leadership may prove more valuable as ideas are developed and refined prior to implementation. Although these propositions seem reasonable, they suggest not only that leadership behavior must change over time but also that successful creative projects may need to rotate leaders. This observation, however, broaches questions about the timing and conditions of leader rotation.

Jaussi, in Chapter 16, examines the significance of leader and follower roles for the success of creative efforts. She argues that different roles, both formal and informal, give rise to different sets of identity. More centrally, she notes that different types of creative efforts, marketing versus research and development, also impose different roles and different role identities. This leads Jaussi to argue that effective leadership of creative efforts will require a balance between leadership roles and creative roles. This observation is noteworthy because it suggests that different styles of leadership may be required in different domains of creative activities.

\section{PART III: DOMAINS}

One might argue that creative leadership is needed in many domains of endeavor. A strong case can be made that creative leadership is needed in politics (Mumford, 2006). A case 
can also be made that creative leadership is needed in primary and secondary education as well as medicine. One area that has received some attention in this regard is executive leadership - a domain that cuts across many fields of endeavor. In Chapter 17, Puccio, Mance, and Acar examine what we know about the need for creative leadership among executives, or senior organizational leaders. They argue that although executives perform many functions, induction of institutional change is a critical function and it is a function that places a premium on leader creative thinking skills. Notably, they argue that such skills may be particularly important as executives seek to lead organizations toward novel goals. This point is of some importance because it suggests that creative thinking skills may be particularly important in change management and the entrepreneurial establishment of new businesses or new lines of products and services.

Executives, of course, are not the people who seek to direct or lead the day-to-day work in organizations. Organizations are layered, often hierarchical structures (Caughron \& Mumford, 2012) and the work done at different levels, and the type of leadership required for creativity, may be quite different (Mumford, Campion, \& Morgeson, 2007). Van Knippenberg (Chapter 18) examines how creative leadership occurs in supervisory and middle-management positions. He argues that in these positions the key requirement for leaders is to motivate creativity on the part of workers, noting that leaders should build a sense of creative self-efficacy and support and reward creative efforts while allowing followers requisite autonomy. This last point is noteworthy because it brings into question the value of transformational leadership for encouraging follower creativity.

We often assume that creative leadership is required of executives and those assuming leadership positions in business. In contrast, our stereotypic view holds that leaders in the military do not need to lead for creativity. Military settings, however, are inherently competitive and military leaders, like coaches, must "out think" the competition - a competition trying to "out think" them. As a result, creative leadership may be critical to the success of military leaders. Connelly and Zaccaro, in Chapter 19, examine the findings emerging from a large-scale, longitudinal study of senior US military leaders. Their findings indicate that creative thinking skills are critical to continuance and performance in a military "up or out" system. More centrally, their observations indicate that leader creative thinking skills, at least in military settings, develop over a rather long period of time. This point is noteworthy because it suggests that systematic interventions, both educational and assignments (work experience), may be needed to develop creative leadership. More centrally, the findings of Connelly and Zaccaro suggest that creative leadership may be particularly important in high-risk environments - environments containing complex and ambiguous challenges.

Oddly, we do not think of academia, colleges and universities as especially high-risk environments. However, the issues confronting leaders in academia are complex, novel, and often of high risk and substantial cost. Thus, like the military, it seems plausible to expect that creative leadership is needed in academic settings. In Chapter 20, Bennich-Björkman in fact makes a compelling case that creative leadership is needed in academic settings. Her work, however, points to three key functions that shape the need for creative leadership in academic settings. First, academic leaders must deal with multiple stakeholders - stakeholders who have very different needs and concerns. Second, the effects of creative leadership in academic settings emerge only over long - very long - periods of time, resulting in substantial uncertainty. Third, academic leaders must deal with multiple constraints 
imposed by many different constituencies. This observation suggests that creative leadership may be at a premium in fields where leaders must weave through and integrate many different constraints as they seek viable creative problem solutions.

Constraints, and their impact on the need for creative leadership, are also evident in the marketing domain. To see this point, think of the length of commercials ( 30 seconds) or the length of magazine advertisements (one page). In fact, these constraints, when combined with the need to get consumer attention, may make creative leadership especially significant. Schmidt and Watts, in Chapter 21, examine creative leadership in the marketing field. Their observations indicate that in marketing, creative leadership occurs within constraints, constraints that set boundaries, where leaders seek to stimulate bounded creativity. This observation is noteworthy because we often equate creativity, and creative leadership, with openness, while at least in marketing creative leadership requires bounding of openness.

We often assume that creativity in the arts also requires openness. As Stokes and Fisher (2005) have pointed out, however, creative work in the arts is often highly constrained by medium and style and is both technical and social - consider the need of artists to promote their work to galleries, museums, or connoisseurs. Ropo, De Paoli, and Bathurst, in Chapter 22, examine creative leadership in the arts through a series of qualitative studies. The clear conclusion that emerges from their studies is that creative leadership in the arts depends on emotional intuition - emotional intuition brought about by listening to others. Thus, creative leadership may require not only a focus on the external world but also a focus on the emotional reactions evident in this world.

Artists, of course, are in some ways similar to, and in some ways different from, scientists and engineers. Hemlin and Olsson (Chapter 23) describe the findings emerging in a study of academic and industrial research and development leaders. Critical incidents were used to identify the behaviors characterizing creative leaders. Their findings indicate that leaders provide expertise and effectively manage and schedule tasks and meetings. These findings remind us of an important point - not only must creative leaders have exceptional expertise, they must also be good managers of both themselves and the team.

\section{CONCLUSIONS}

Our foregoing observations point to a key straightforward conclusion. The effective leadership of creative efforts may, in fact, be the single most complex form of leadership. To clarify this point, consider a few observations made earlier by the authors of this handbook. Leaders of creative efforts must have exceptional technical skill (Hemlin \& Olsson, Chapter 23) but leaders of creative efforts must be able to "sell" or champion their projects (Markham \& Smith, Chapter 4). Leaders of creative efforts must listen and learn (Kazanjian, Chapter 3; Ropo et al., Chapter 22) but, by the same token, they must structure the work being done (Ligon \& Derrick, Chapter 10). Leaders of creative efforts must be supportive (Stephens \& Carmeli, Chapter 13) even as they seek concrete, albeit innovative, new products (Kratzer \& Michelfelder, Chapter 9). Leaders of creative efforts must work within constraints (Connelly \& Zaccaro, Chapter 19) even as they envision, forecast, future unfolding events and the potential of new ideas and new products (Mumford et al., Chapter 2). These varied and conflicting requirements for creative leadership point not 
only to the complexity of leading for creativity but also to the substantial demands made on those asked to lead creative efforts.

The demands made on those asked to lead creative efforts, and the complexity of creative leadership, are noteworthy because they underscore the need for systematic, sustained, well-thought-out research. For example, it seems clear that the domain in which creative leaders are asked to operate is a key concern. Motivating others may be important for mid-level business leaders (van Knippenberg, Chapter 18) but it may be less important for creative leadership in academic settings (Bennich-Björkman, Chapter 20). Thus, studies of creative leadership must be bounded to specific domains. Not only must studies of creative leadership be bounded to domain, they must also be bounded to the stage of idea development - a point made in Lovelace et al.'s (Chapter 15) observations about charismatic, ideological, and pragmatic leadership.

Of course, these observations imply we cannot assume that general models of leadership can be arbitrarily applied in the study of creative leadership. In fact, Rosing's observations (Chapter 12) with respect to transformational leadership and its impact on follower creativity underscore this point. As a result, it is clear we need research that attempts to tailor extant models of leadership to the unique demands made on those asked to lead creative efforts. Olsson's observations on leader-member exchange in incidents of creative leadership work (Chapter 11) reflects some important initial work along these lines.

In addition, the unique demands imposed on those asked to lead creative efforts pose a host of interesting new research questions. For example, Friedrich and Zhong's work (Chapter 14) broaches questions bearing on how collectives should be defined at different stages of creative efforts. The observations of Watts et al. (Chapter 5) point to the need to understand when, and why, creative leaders will tolerate failure in idea evaluation. The observations of Bennich-Björkman (Chapter 20) point to the need for studies examining what constraints the leaders of creative efforts attend to and how they work on or work within these constraints. The observations of Mumford et al. (Chapter 2) point to the importance of studies of both forecasting and opportunistic plan modification in attempts to understand creative leadership.

We believe that one key contribution of this handbook is that it not just summarizes what we know about effective leadership of creative efforts, it also points to some important new directions for this research. This research is not simply of interest for academic reasons. It provides guidelines for those asked to lead creative efforts and provides the basis for systematic developmental interventions that will prepare people to lead creative efforts (Isaksen, Chapter 7). Given that the demands made on those asked to lead creative efforts and the fact that the success of the creative efforts firms seek depends so strongly on effective leadership, such research provides a crucial piece of infrastructure that is of great value to many organizations. We hope that this handbook provides a background for further research that will allow us to understand and make the effective leadership of creative efforts possible.

\section{ACKNOWLEDGEMENTS}

We would like to thank Tristan McIntosh, Logan Watts, and Logan Steele for their contributions to this chapter. 


\section{REFERENCES}

Agars, M.D., Kaufman, J.C., Deane, A., \& Smith, B. (2012). Fostering individual creativity through organizational context: A review of recent research and recommendations for organizational leaders. In M.D. Mumford (Ed.). Handbook of organizational creativity (pp. 271-291). London: Academic Press.

Amabile, T.M. (1996). Creativity in context. Boulder: Westview Press.

Amabile, T.M., Conti, R., Coon, H., Lazenby, J., \& Herron, M. (1996). Assessing the work environment for creativity. Academy of Management Journal, 39, 1154-1184.

Andrews, F.M., \& Farris, G.F. (1967). Supervisory practices and innovation in scientific teams. Personnel Psychology, 20, 497-515.

Baer, M. (2012). Putting creativity to work: The implementation of creative ideas in organizations. Academy of Management Journal, 55, 1102-1119.

Barnowe, J.T. (1975). Leadership and performance outcomes in research organizations: The supervisor of scientists as a source of assistance. Organizational Behavior and Human Performance, 14, 264-280.

Barrett, J.D., Vessey, W.B., Griffith, J.A., Mracek, D., \& Mumford, M.D. (2014). Predicting scientific creativity: The role of adversity, collaborations, and work strategies. Creativity Research Journal, 26, 39-52.

Bass, B.M. (1985). Leadership beyond expectations. New York: Free Press.

Carmeli, A., Reiter-Palmon, R., \& Ziv, E. (2010). Inclusive leadership and employee involvement in creative tasks in the workplace: The mediating role of psychological safety. Creativity Research Journal, 22, 250-260.

Caughron, J.J., \& Mumford, M.D. (2012). Embedded leadership: How do a leader's superiors impact middlemanagement performance? The Leadership Quarterly, 23, 342-353.

Cohen, W.M., \& Levinthal, D.A. (1990). Absorptive capacity: A new perspective on learning and innovation. Administrative Science Quarterly, 35, 128-152.

Damanpour, F., \& Schneider, M. (2006). Phases of the adoption of innovation in organizations: Effects of environment, organization, and top managers. British Journal of Management, 17, 215-236.

Dean, J.W., \& Sharfman, M.P. (1996). Does decision process matter? A study of strategic decision-making effectiveness. Academy of Management Journal, 39, 368-396.

Denti, L., \& Hemlin, S. (2012). Leadership and innovation in organizations: A systematic review of factors that mediate or moderate the relationship. International Journal of Innovation Management, 16, 1240007-1-1240007-20.

Dess, G.G., \& Pickens, J.C. (2000). Changing roles: Leadership in the 21st century. Organizational Dynamics, $28,18-34$.

Eisenbeiss, S.A., van Knippenberg, D., \& Boerner, S. (2008). Transformational leadership and team innovation: Integrating team climate principles. Journal of Applied Psychology, 93, 1438-1446.

Feist, G.J. (1998). A meta-analysis of personality in scientific and artistic creativity. Personality and Social Psychology Review, 2, 290-309.

Fleishman, E.A. (1953). The description of supervisory behavior. Journal of Applied Psychology, 37, 1-6.

Fleishman, E.A., Mumford, M.D., Zaccaro, S.J., Levin, K.Y., Korotkin, A.L., \& Hein, M.B. (1992). Taxonomic efforts in the description of leadership behavior: A synthesis and functional interpretation. The Leadership Quarterly, 2, 245-287.

Friedrich, T.L., Vessey, W.B., Schuelke, M.J., Mumford, M.D., Yammarino, F.J., \& Ruark, G.A. (2014). Collectivistic leadership and George C. Marshall: A historiometric analysis of career events. The Leadership Quarterly, 25, 449-467.

Friedrich, T.L., Vessey, W.B., Schuelke, M.J., Ruark, G.A., \& Mumford, M.D. (2009). A framework for understanding collective leadership: The selective utilization of leader and team expertise within networks. The Leadership Quarterly, 20, 933-958.

Graen, G.B., \& Uhl-Bien, M. (1995). Relationship-based approach to leadership: Development of leadermember exchange (LMX) theory of leadership over 25 years: Applying multi-domain approach. The Leadership Quarterly, 6, 219-247.

Hemlin, S. (2009). Creative knowledge environments: An interview study with group members and group leaders of university and industry R\&D groups in biotechnology. Creativity and Innovation Management, $18,278-285$.

Hemlin, S., \& Olsson, L. (2011). Creativity stimulating leadership: A critical incident study of leaders' influence on creativity in R\&D groups. Creativity and Innovation Management, 20, 49-58.

Hirst, G., van Knippenberg, D., \& Zhou, J. (2009). A cross-level perspective on employee creativity: Goal orientation, team learning behavior, and individual creativity. Academy of Management Journal, 52, $280-293$.

Howell, J.M., \& Boies, K. (2004). Champions of technological innovation: The influence of contextual knowledge, role orientation, idea generation, and idea promotion on champion emergence. The Leadership Quarterly, 15, 123-143.

Hülsheger, U.R., Anderson, N., \& Salgado, J.F. (2009). Team-level predictors of innovation at work: A 
comprehensive meta-analysis spanning three decades of research. Journal of Applied Psychology, 94, $1128-1145$.

Hunter, S.T., Bedell, K.E., \& Mumford, M.D. (2007). Climate for creativity: A quantitative review. Creativity Research Journal, 19, 69-90.

Jaussi, K.S. \& Dionne, S.D. (2003). Leading for creativity: The role of unconventional behavior. The Leadership Quarterly, 14, 351-368.

Keller, R.T. (2006). Transformational leadership, initiating structure, and substitutes for leadership: A longitudinal study of research and development project team performance. Journal of Applied Psychology, 91, 202-210.

Kim, Y., Min, B., \& Cha, J. (1999). The roles of R\&D team leaders in Korea: A contingent approach. $R \& D$ Management, 29, 153-166.

Koberg, C.S., Uhlenbruck, N., \& Sarason, Y. (1996). Facilitators of organizational innovation: The role of lifecycle stage. Journal of Business Venturing, 11, 133-149.

Mainemelis, C., Kark, R., \& Epitropaki, O. (2015). Creative leadership: A multi-context conceptualization. The Academy of Management Annals, 9, 393-482.

Marta, S., Leritz, L.E., \& Mumford, M.D. (2005). Leadership skills and the group performance: Situational demands, behavioral requirements, and planning. The Leadership Quarterly, 16, 97-120.

Medeiros, K.E., Partlow, P.J., \& Mumford, M.D. (2014). Not too much, not too little: The influence of constraints on creative problem solving. Psychology of Aesthetics, Creativity, and the Arts, 8, 198-210.

Medeiros, K.E., Watts, L.L., \& Mumford, M.D. (2016). Thinking inside the box: Educating leaders to manage constraints. In C. Zhou (Ed.), Handbook of research on creative problem-solving skill development in higher education, Hershey: IGI Global.

Mintzberg, H. (1991). Learning-1, planning-0: reply to Igor Ansoff. Strategic Management Journal, 12, $463-466$.

Mumford, M.D. (2006). Pathways to outstanding leadership: A comparative analysis of charismatic, ideological and pragmatic leaders. Mahwah: Erlbaum.

Mumford, M.D., \& Hunter, S.T. (2005). Innovation in organizations: A multi-level perspective on creativity. In F.J. Yammarino \& F. Dansereau (Eds.), Research in multi-level issues (Vol. 4, pp. 11-74). Bingley: Emerald.

Mumford, M.D., Bedell-Avers, K.E., \& Hunter, S.T. (2008). Planning for innovation: A multi-level perspective. In F.J. Yammarino \& F. Dansereau (Eds.), Research in multi-level issues (Vol. 7, pp. 107-154). Bingley: Emerald.

Mumford, T.V., Campion, M.A., \& Morgeson, F.P. (2007). The leadership skills strataplex: Leadership skill requirements across organizational levels. The Leadership Quarterly, 18, 154-166.

Mumford, M.D., Gibson, C., Giorgini, V., \& Mecca, J.T. (2014). Leading for creativity: People, products, and systems. In D.V. Day (Ed.), Oxford handbook of leadership and organizations (pp. 757-782). New York: Oxford University Press.

Mumford, M.D., Medeiros, K.E., \& Partlow, P.J. (2012). Creative thinking: Processes, strategies, and knowledge. The Journal of Creative Behavior, 46, 30-47.

Mumford, M.D., Scott, G.M., Gaddis, B., \& Strange, J.M. (2002). Leading creative people: Orchestrating expertise and relationships. The Leadership Quarterly, 13, 705-750.

Nohria, N., \& Gulati, R. (1996). Is slack good or bad for innovation? Academy of Management Journal, 39 , $1245-1264$.

O'Connor, G.C. (1998). Market learning and radical innovation: A cross case comparison of eight radical innovation projects. Journal of Product Innovation Management, 15, 151-166.

Oldham, G.R., \& Cummings, A. (1996). Employee creativity: Personal and contextual factors at work. Academy of Management Journal, 39, 607-634.

Pelz, D.C., \& Andrews, F.M. (1966). Autonomy, coordination, and simulation in relation to scientific achievement. Behavioral Science, 12, 89-97.

Scott, S.G., \& Bruce, R.A. (1998). Following the leader in R\&D: The joint effect of subordinate problem-solving style and leader-member relations on innovative behavior. IEEE Transactions on Engineering Management, $45,3-10$.

Stokes, P.D., \& Fisher, D. (2005). Selection, constraints, and creativity case studies: Max Beckmann and Philip Guston. Creativity Research Journal, 17, 283-291.

Tierney, P., \& Farmer, S.M. (2002). Creative self-efficacy: Its potential antecedents and relationship to creative performance. Academy of Management Journal, 45, 1137-1148.

Tierney, P., Farmer, S.M., \& Graen, G.B. (1999). An examination of leadership and employee creativity: The relevance of traits and relationships. Personnel Psychology, 52, 591-620.

Weisberg, R.W., \& Hass, R. (2007). Commentaries: We are all partly right: Comment on Simonton. Creativity Research Journal, 19, 345-360.

West, M., \& Sacramento, C. (2012). Creativity and innovation: The role of team and organizational climate. In M.D. Mumford (Ed.), Handbook of organizational creativity (pp. 359-385). London: Academic Press

Zhang, X., \& Bartol, K.M. (2010). Linking empowering leadership and employee creativity: The influence of psychological empowerment, intrinsic motivation, and creative process engagement. Academy of Management Journal, 53, 107-128. 
Michael D. Mumford, Sven Hemlin, and Tyler J. Muthearn - 9781784715465 Downloaded from PubFactory at 04/26/2023 06:14:44AM via free access 